\title{
Practice survey: adherence monitoring and intervention in pediatric gastroenterology and hepatology
}

This article was published in the following Dove Press journal:

Therapeutics and Clinical Risk Management

\author{
Michele H Maddux ${ }^{1,2}$ \\ Shawna Ricks ${ }^{2}$ \\ Julie A Bass ${ }^{2}$ \\ James F Daniel ${ }^{2}$ \\ Ellen Carpenter ${ }^{2}$ \\ Kimberely Radford ${ }^{2}$ \\ 'Division of Developmental and \\ Behavioral Sciences, Children's \\ Mercy-Kansas City, Kansas City, MO, \\ USA; ${ }^{2}$ Division of Gastroenterology, \\ Children's Mercy-Kansas City, Kansas \\ City, MO, USA
}

\begin{abstract}
Purpose: Despite significant medication nonadherence rates among youth with pediatric gastroenterology and hepatology disorders, little is known about current adherence practices in pediatric gastroenterology care. This study summarizes current practices surrounding adherence monitoring and intervention in pediatric gastrointestinal (GI) and hepatologic care in the USA.

Participants and methods: One hundred and fifty-four pediatric GI providers completed an online survey designed to examine current practices surrounding adherence monitoring and intervention, specific strategies used to monitor and treat poor adherence, and the barriers currently experienced in relation to adherence monitoring and intervention.

Results: Practices varied greatly in terms of when and how patient adherence is monitored and by whom; however, physicians and nursing professionals take primary responsibility for adherence monitoring. Approximately $25 \%$ utilize screeners to assess adherence, and most participants use patient and caregiver reports as a primary measure of adherence. Most participants rated their level of adherence monitoring and intervention as fair to poor. While most participants perceive adherence monitoring to be very important in clinical practice, only $20.8 \%$ perceive being able to significantly modify patient adherence.

Conclusion: There exists great variability in adherence monitoring and intervention practices across pediatric GI providers. Greater understanding of current adherence practices can inform future clinical efforts.
\end{abstract}

Keywords: adherence, screening, clinical practice, intervention, compliance

\section{Introduction}

Poor adherence to treatment regimens, which refers to the extent to which a person's behavior coincides with medical advice, is a significant problem across pediatric conditions. In fact, poor adherence has been deemed to be the primary cause of treatment failure in pediatrics. ${ }^{1}$ It carries considerable implications for morbidity and mortality, cost-effectiveness of medical care, and disease management decisions by health care providers. ${ }^{2}$ Poor adherence among chronically ill youth is associated with significantly poorer quality of life, impairments in psychosocial and physical functioning, greater absenteeism from daily activities, and greater health care utilization. ${ }^{2,3}$ Across pediatric conditions, extant literature suggests that $\sim 50 \%$ of children and $65 \%-75 \%$ of adolescents are nonadherent to prescribed medical regimens. ${ }^{3-5}$

In pediatric gastroenterology and hepatology, most adherence research has focused on pediatric inflammatory bowel disease (IBD) and pediatric liver disease. Management of these medical conditions can be time consuming and complex, as treatment regimens can include a combination of oral medication, IV medication, as well
Correspondence: Michele H Maddux

Division of Developmental and Behaviora Sciences, Division of Gastroenterology,

Children's Mercy-Kansas City,

240I Gillham Road, Kansas City,

MO 64109, USA

$\mathrm{Tel}+\mathrm{I} 8162343862$

Fax + I 8163029898

Emailmhmaddux@cmh.edu
Therapeutics and Clinical Risk Management 2018:14 I227-1234

1227

Dovepress f $y$ in $\mathbf{0}$

http://dx,doi.org/10.2147/TCRM.S15961t

(c) (1) (8) $\odot 2018$ Maddux et al. This work is published and licensed by Dove Medical Press Limited. The full terms of this license are available at https://www.dovepress.com/terms.php cC) and incorporate the Creative Commons Attribution - Non Commercial (unported, v3.0) License (http://creativecommons.org/licenses/by-nc/3.0/). By accessing the work you hereby accept the Terms. Non-commercial uses of the work are permitted without any further permission from Dove Medical Press Limited, provided the work is properly attributed. For permission for commercial use of this work, please see paragraphs 4.2 and 5 of our Terms (https://www.dovepress.com/terms.php). 
dietary and lifestyle modifications (eg, restricted physical activity). Empirical research in pediatric IBD has demonstrated nonadherence prevalence as high as $64 \%-88 \%{ }^{6}$ The most commonly identified barriers to adherence in pediatric IBD include forgetting, interference with other activities, difficulty swallowing pills, and not being at home. ${ }^{7}$ Some families also intentionally do not follow the IBD treatment regimen, particularly in the absence of disease symptoms, to simplify the treatment regimen, and/or to alleviate side effects. ${ }^{8}$ Yet, poor adherence to oral medication in IBD has been linked to a fivefold increased risk of relapse, ${ }^{9}$ a $12.5 \%$ increase in annual health care costs, ${ }^{10}$ and greater health care use (ie, hospitalizations, emergency department visits, outpatient visits $\left.{ }^{3}\right)$. Among pediatric liver transplant recipients, nonadherence rates have been found as high as $42 \%-50 \%$ within 5 years following transplant. ${ }^{11}$ Poor adherence to oral medication has also been linked to significantly greater graft loss in adolescent liver transplant recipients. ${ }^{12}$ These nonadherence rates are alarming, especially considering that even minor deviations from a dosing schedule can be associated with negative health outcomes. Also, nonadherence in the US costs between $\$ 100$ and $\$ 300$ billion yearly, which amounts to $3 \%-10 \%$ of total US health care costs. ${ }^{4,13}$

In light of high nonadherence rates in pediatric gastroenterology and hepatology and the impact on patient outcomes, it is imperative to monitor adherence as part of standard clinical care and provide targeted intervention. Such a proactive approach is likely to identify adherence difficulties early on, thereby ensuring that poor adherence does not place youth at increased risk of morbidity and mortality. In spite of the aforementioned evidence of prevalent nonadherence, little is currently known about clinical practices around adherence to prescribed treatment regimens in pediatric gastroenterology and hepatology. This project is aimed at characterizing current practices surrounding adherence monitoring and intervention in pediatric gastrointestinal (GI) and hepatologic care in the USA.

\section{Participants and methods Ethical considerations}

All study procedures were approved by the Institutional Review Board at Children's Mercy-Kansas City. Data were collected anonymously, and consent to participate was implied by voluntary participation of the study survey.

\section{Participants and procedures}

Providers were identified from several sources: 1) the North American Society for Pediatric Gastroenterology,
Hepatology, and Nutrition, 2) the Association of Pediatric Gastroenterology and Nutrition Nurses, and 3) an internet search of pediatric GI/hepatology providers across the USA. These sources included private practice providers as well as those within hospitals or academic medical centers. Inclusion criteria included specialty medical care in the field of pediatric gastroenterology and/or hepatology, and English fluency.

Once participants were identified, study data were collected and managed using Research Electronic Data Capture (REDCap) electronic data capture tools hosted by the study site. ${ }^{14}$ REDCap is a secure, web-based application designed to support data capture for research studies, providing 1) an intuitive interface for validated data entry; 2) audit trails for tracking data manipulation and export procedures; 3) automated export procedures for seamless data downloads to common statistical packages; and 4) procedures for importing data from external sources. Participants were sent a REDCapgenerated email link to the survey with an invitation to participate and instructions for completing the survey. Two waves of reminder emails automatically generated within REDCap were sent to all participants 2- and 4-weeks after the initial email invitation was sent.

\section{Measure}

A 36-item survey was developed by authors of this study. The survey was designed to examine adherence-focused clinical practices including but not limited to, the involvement of various disciplines (eg, physician assistant, nurses, social workers, psychologists) in adherence monitoring and intervention, current practices surrounding adherence monitoring and intervention, specific strategies used to monitor and treat poor adherence, and the barriers currently experienced in relation to adherence monitoring and intervention. The definition of adherence according to the World Health Organization was included; "Adherence is defined as the extent to which a person's behavior coincides with medical advice. This might include taking medication, following diets, or implementing lifestyle changes." Content was developed on the basis of extant literature that outlined best practice clinical guidelines for adherence monitoring and intervention, and common barriers to implementation. The questionnaire was reviewed for content and clinical utility by a group of pediatric providers (ie, pediatric gastroenterologist, advance practice nurse) who provided specialty medical care in pediatric gastroenterology and hepatology, and were programmatically involved in adherence-focused clinical care among this pediatric patient population. 


\section{Statistical analyses}

Frequency data was calculated as percentages to summarize feedback obtained across each survey item. Descriptive statistics, including means and standard deviations, were calculated for survey items rated on a Likert scale. Group differences were examined via analysis of variance tests. Analyses were conducted in SPSS 23.0 (SPSS Inc., Chicago, IL, USA).

\section{Results}

\section{Participant and practice characteristics}

A total of 154 professionals, representing 83 distinct practices/ institutions, completed the survey. Most participants were physicians (49.4\%) with $>15$ years of practice $(40.9 \%)$, practicing within children's hospital settings, either freestanding or housed within a larger hospital (91.5\%; Table 1). Most participants practiced in a setting with $>500$ patients (79.9\%), with various provider types other than physicians

Table I Participant characteristics and practice settings $(n=\mid 54)$

\begin{tabular}{|c|c|}
\hline Characteristic & $\%(n)$ \\
\hline Gender (female) & $63.2(96)$ \\
\hline \multicolumn{2}{|l|}{ Number of years in clinical practice } \\
\hline$\leq 5$ years & $25.3(39)$ \\
\hline $6-15$ years & $33.8(52)$ \\
\hline$>15$ years & $40.9(63)$ \\
\hline \multicolumn{2}{|l|}{ Geographic location of practice } \\
\hline West & $16.9(26)$ \\
\hline Southwest & $5.8(9)$ \\
\hline Rocky Mountains/plains & $5.2(8)$ \\
\hline Midwest & $35.1(54)$ \\
\hline Southeast & $15.6(24)$ \\
\hline Middle Atlantic & $14.3(22)$ \\
\hline New England & $7.1(1 \mathrm{I})$ \\
\hline \multicolumn{2}{|l|}{ Practice setting } \\
\hline Children's hospital, free-standing & $51.9(80)$ \\
\hline Children's hospital, located within a larger hospital & $39.6(61)$ \\
\hline Private practice & $6.5(10)$ \\
\hline $\begin{array}{l}\text { Other (eg, free-standing outpatient clinic } \\
\text { for children's specialties, university hospital } \\
\text { department of psychiatry) }\end{array}$ & $1.9(3)$ \\
\hline \multicolumn{2}{|l|}{ Profession } \\
\hline Physician & $49.4(76)$ \\
\hline Physician assistant & $0.0(0)$ \\
\hline Fellow & $2.6(4)$ \\
\hline Nurse & $5.2(8)$ \\
\hline Nurse practitioner & $20.1(31)$ \\
\hline Psychologist & $18.2(28)$ \\
\hline Social worker & $3.2(5)$ \\
\hline Nutritionist/dietician & $0.0(0)$ \\
\hline Program coordinator & I.3 (2) \\
\hline Medical assistant & $0.0(0)$ \\
\hline Other & $0.0(0)$ \\
\hline
\end{tabular}

Table I (Continued)

\begin{tabular}{|c|c|}
\hline Characteristic & $\%(n)$ \\
\hline \multicolumn{2}{|l|}{ Patient population age range } \\
\hline Children ( $0-12$ years) & $99.4(153)$ \\
\hline Adolescents ( $13-18$ years) & $97.4(150)$ \\
\hline Young adults ( $19-25$ years) & $65.6(101)$ \\
\hline Adults (26+ years) & $3.2(5)$ \\
\hline \multicolumn{2}{|l|}{ Size of gastroenterology/hepatology patient } \\
\hline \multicolumn{2}{|l|}{ population at practice } \\
\hline $0-100$ & $4.5(7)$ \\
\hline $10 \mid-200$ & $1.9(3)$ \\
\hline $20 I-300$ & $5.2(8)$ \\
\hline $30 I-400$ & $3.2(5)$ \\
\hline $40 I-500$ & $5.2(8)$ \\
\hline $501+$ & $79.9(123)$ \\
\hline \multicolumn{2}{|l|}{ Health conditions treated } \\
\hline Inflammatory bowel disease & $77.9(120)$ \\
\hline Celiac disease & $75.3(116)$ \\
\hline Functional abdominal pain & $81.8(126)$ \\
\hline Eosinophilic esophagitis & $76.0(117)$ \\
\hline Eosinophilic gastroenteritis & $62.3(96)$ \\
\hline Motility disorders & $59.1(91)$ \\
\hline Gastroesophageal reflux & $79.9(123)$ \\
\hline Functional dyspepsia & $74.0(1 \mid 4)$ \\
\hline Short bowel/short gut syndrome & $61.7(95)$ \\
\hline Irritable bowel syndrome & $79.2(122)$ \\
\hline $\begin{array}{l}\text { Familial adenomatous polyposis/polyposis } \\
\text { syndromes }\end{array}$ & $51.3(79)$ \\
\hline Colorectal cancer & $14.3(22)$ \\
\hline Liver disease & $63.0(97)$ \\
\hline Liver transplant & $32.5(50)$ \\
\hline Constipation & $83.8(129)$ \\
\hline Encopresis & $79.2(122)$ \\
\hline Failure to thrive & $77.9(120)$ \\
\hline Cyclic vomiting & $72.7(112)$ \\
\hline $\begin{array}{l}\text { Other (eg, pancreatic diseases, feeding disorders, } \\
\text { rumination disorder) }\end{array}$ & I5.6 (24) \\
\hline \multicolumn{2}{|l|}{ Providers seeing patients in practice } \\
\hline Physician & $95.5(147)$ \\
\hline Physician assistant & II.0 (I7) \\
\hline Fellow & $47.4(73)$ \\
\hline Nurse & $53.9(83)$ \\
\hline Nurse practitioner & $74.0(114)$ \\
\hline Psychologist & $45.5(70)$ \\
\hline Social worker & $53.9(83)$ \\
\hline Nutritionist/dietician & $74.7(115)$ \\
\hline Program coordinator & $12.3(19)$ \\
\hline Medical assistant & $33.8(52)$ \\
\hline $\begin{array}{l}\text { Other (eg, fitness trainer, occupational and speech } \\
\text { therapist, surgeon, pharmacist) }\end{array}$ & $9.1(14)$ \\
\hline
\end{tabular}

seeing patients (eg, nurse practitioner, nutritionist/dietician, psychologist, social worker).

\section{Adherence monitoring practices}

Most participants (74.7\%) reported monitoring patient adherence as part of standard clinical care, with approximately half of this subset monitoring adherence with all 
patients (Table 2). Among this subset, monitoring patient adherence is largely the responsibility of the physician $(75.3 \%)$ or nurse practitioner (47.4\%), and this is largely done at every patient visit (70.1\%). Approximately one-fourth of

Table 2 Adherence monitoring practices $(n=154)$

\begin{tabular}{|c|c|}
\hline Practice characteristic & $\%(n)$ \\
\hline Monitoring as standard clinical care (\% yes) & $74.7(115)$ \\
\hline \multicolumn{2}{|l|}{ Patient criteria for monitoring } \\
\hline All patients & $55.8(86)$ \\
\hline $\begin{array}{l}\text { Subset (eg, patients with IBD, celiac disease, or liver } \\
\text { transplant, patients with adherence difficulties, patients } \\
\text { on medication for which drug levels are monitored) }\end{array}$ & $44.2(68)$ \\
\hline \multicolumn{2}{|l|}{ Tasked with monitoring patient adherence } \\
\hline Physician & $75.3(116)$ \\
\hline Physician assistant & $8.4(13)$ \\
\hline Fellow & $26.0(40)$ \\
\hline Nurse & $42.2(65)$ \\
\hline Nurse practitioner & $47.4(73)$ \\
\hline Psychologist & $19.5(30)$ \\
\hline Social worker & $12.3(19)$ \\
\hline Nutritionist/dietician & $11.0(17)$ \\
\hline Program coordinator & $3.9(6)$ \\
\hline Medical assistant & $5.2(8)$ \\
\hline Other (eg, pharmacist, research coordinator) & $4.5(7)$ \\
\hline No one is responsible for monitoring adherence & $12.3(19)$ \\
\hline \multicolumn{2}{|l|}{ Monitoring frequency } \\
\hline Once yearly & $3.2(5)$ \\
\hline Twice yearly & $1.3(2)$ \\
\hline At every patient visit & $70.1(108)$ \\
\hline Depends on the patient & $20.8(32)$ \\
\hline Never & $7.1(11)$ \\
\hline Other & $0.6(I)$ \\
\hline Use of screening measures (\% yes) & $24.7(38)$ \\
\hline \multicolumn{2}{|l|}{ Screening measure type } \\
\hline MMAS & $12.3(19)$ \\
\hline MAM & $0.6(1)$ \\
\hline BMQ & $4.5(7)$ \\
\hline MARS & $1.3(2)$ \\
\hline AMBS/PMBS & $0.6(1)$ \\
\hline Other (eg, TRAQ, measure developed internally) & $7.8(12)$ \\
\hline \multicolumn{2}{|l|}{ Screening measure frequency } \\
\hline Once yearly & $1.3(2)$ \\
\hline Twice yearly & $0.0(0)$ \\
\hline At every patient visit & $21.4(33)$ \\
\hline Depends on the patient & $2.6(4)$ \\
\hline Never & $0.0(0)$ \\
\hline Other & $1.3(2)$ \\
\hline \multicolumn{2}{|l|}{ Screening measure data usage } \\
\hline Reviewed with patient and family & $18.8(29)$ \\
\hline Reviewed by medical team & $17.5(27)$ \\
\hline $\begin{array}{l}\text { Used to make referrals for targeted adherence } \\
\text { intervention }\end{array}$ & $5.2(8)$ \\
\hline Used to develop action plan to improve adherence & $12.3(19)$ \\
\hline Used to make changes to patient's treatment regimen & $13.0(20)$ \\
\hline Research & $5.2(8)$ \\
\hline Quality improvement & $10.4(16)$ \\
\hline Data not currently being used & $0.6(I)$ \\
\hline
\end{tabular}

Table 2 (Continued)

\begin{tabular}{ll}
\hline Practice characteristic & $\%$ (n) \\
\hline Additional monitoring/measurement methods & \\
Patient self-report & $87.7(135)$ \\
Parent/caregiver report & $78.6(121)$ \\
Provider estimates & $20.1(3 \mathrm{I})$ \\
Pharmacy records & $31.2(48)$ \\
Pill counts & $1.9(3)$ \\
Blood assays/lab values & $51.3(79)$ \\
Electronic monitoring (eg, electronic pill bottle, & $0.6(1)$ \\
electronic pill box) & \\
Response to treatment/medication & $49.4(76)$ \\
Disease severity & $24.7(38)$ \\
Other (eg, home videos) & $1.3(2)$ \\
None & $5.8(9)$ \\
Rating of adherence monitoring in clinic/practice & $2.96 \pm 1.29$ \\
(mean \pm SD) & \\
Poor & $9.1(14)$ \\
Fair & $32.5(50)$ \\
Good & $28.6(44)$ \\
Very good & $20.8(32)$ \\
Excellent & $1.3(2)$ \\
N/A: we do not monitor adherence & $7.8(12)$ \\
\hline
\end{tabular}

Abbreviations: IBD, inflammatory bowel disease; MMAS, morisky medication adherence scale; MAM, medical adherence measure; BMQ, brief medication questionnaire; MARS, medication adherence rating scale; AMBS/PMBS, adolescent/ parent medication barriers scale, TRAQ, transition readiness assessment questionnaire; N/A, not applicable.

participants $(24.7 \%)$ endorsed using a validated (ie, psychometrically tested for reliability and validity) screener to assess patient adherence, which is typically reviewed with the patient and family (18.8\%), reviewed by the medical team (17.5\%), and/or used to make changes to patients' treatment regimen (13.0\%) or develop action plans (12.3\%). Most frequently used methods for monitoring adherence included patient self-report (87.7\%), parent/caregiver report (78.6\%), blood assays/lab values (51.3\%), and patient response to treatment/medication (ie, changes in a patient's symptoms while on a medication) (49.4\%).

\section{Adherence intervention practices}

Table 3 shows that $70.1 \%$ of participants reported providing adherence-focused intervention to patients with poor/low adherence. Half of respondents defined poor/low adherence as missing at least $25 \%$ of medication doses, and another $37 \%$ defined poor/low adherence as missing at least $50 \%$ of medication doses. The most frequently endorsed types of adherence intervention included education on consequences of poor adherence $(64.3 \%)$, education on strategies for improving adherence $(61.7 \%)$, identifying adherence barriers $(52.6 \%)$, and simplifying the treatment regimen (48.7\%). Such intervention is provided largely by nursing 
Table 3 Adherence intervention practices $(n=154)$

\begin{tabular}{|c|c|}
\hline Practice characteristic & $\%(n)$ \\
\hline $\begin{array}{l}\text { Provision of adherence intervention for poor adherence } \\
\text { (\% yes) }\end{array}$ & $70.1(108)$ \\
\hline \multicolumn{2}{|l|}{ Adherence intervention type } \\
\hline Education on consequences of poor adherence & $64.3(99)$ \\
\hline Education on strategies for improving adherence & $61.7(95)$ \\
\hline Modeling appropriate way to carry out treatment plan & $20.1(31)$ \\
\hline Pill swallowing training & $26.0(40)$ \\
\hline Increased provider supervision/monitoring & $20.8(32)$ \\
\hline Increased parental supervision/monitoring & $35.1(54)$ \\
\hline Written treatment plans & $32.5(50)$ \\
\hline Simplifying treatment regimen & $48.7(75)$ \\
\hline Changing treatment regimen & $33.1(5 I)$ \\
\hline Identifying adherence barriers & $52.6(8 I)$ \\
\hline Problem solving to target adherence barriers & $45.5(70)$ \\
\hline Use of electronic reminders (eg, alarm, texting) & $27.9(43)$ \\
\hline $\begin{array}{l}\text { Electronic monitoring (eg, MemsCap, Maya pillbox, } \\
\text { MedSignals) }\end{array}$ & $3.2(5)$ \\
\hline Other (eg, referral to Behavioral Medicine) & $0.6(1)$ \\
\hline \multicolumn{2}{|l|}{ Intervention provider } \\
\hline Physician & $31.2(48)$ \\
\hline Nursing staff & $51.9(80)$ \\
\hline Nurse practitioner & $37.7(58)$ \\
\hline Psychologist & $26.6(4 I)$ \\
\hline Social worker & $14.9(23)$ \\
\hline Other (eg, child life specialist, pharmacist, OT) & $4.5(7)$ \\
\hline \multicolumn{2}{|l|}{ Intervention modality } \\
\hline Face-to-face during clinic visit & $70.1(108)$ \\
\hline Over the phone & $34.4(53)$ \\
\hline Via educational handouts & $22.1(34)$ \\
\hline Via web-based education & $3.9(6)$ \\
\hline Other & $0.0(0)$ \\
\hline $\begin{array}{l}\text { Rating of adherence intervention in clinic/practice } \\
(\text { mean } \pm \text { SD) }\end{array}$ & $2.84 \pm 1.29$ \\
\hline Poor & $14.3(22)$ \\
\hline Fair & $27.9(43)$ \\
\hline Good & $32.5(50)$ \\
\hline Very good & $16.9(26)$ \\
\hline Excellent & $1.9(3)$ \\
\hline N/A: we do not provide adherence intervention & $6.5(10)$ \\
\hline
\end{tabular}

Abbreviations: OT, occupational therapist; N/A, not applicable.

staff $(51.9 \%)$, nurse practitioners $(37.7 \%)$ or physicians $(31.2 \%)$, and usually conducted face-to-face during clinic visits (70.1\%).

Overall, participants were asked to rate the level of adherence monitoring in their clinic/practice, from "poor" to "excellent". On average, ratings were fair $(32.5 \%)$ or good (28.6\%; Table 2). Participants were also asked to rate the level of adherence intervention in their clinic/practice, on the same scale. On average, ratings were fair $(27.9 \%)$ or good (32.5\%; Table 3). Finally, participants were asked what might facilitate greater adherence monitoring and intervention in their clinic/practice. The most frequently endorsed responses were more staff/manpower (63\%), education on evidence-based screening measures (55.2\%), and education on evidence-based interventions (56.5\%).

\section{General attitudes toward adherence practices}

Overall, most participants felt that adherence intervention should be the responsibility of the physician (91.6\%), nursing staff (73.4\%), or nurse practitioner (70.1\%). Approximately half of the participants perceived that psychologists and social workers should be responsible for providing adherence-focused intervention. In terms of nonadherence prevalence, most participants $(90.3 \%)$ rated that no more than half of the children aged $0-12$ take $<80 \%$ of their prescribed medication, and $66.2 \%$ rated that no more than half of the adolescents take $<80 \%$ of their prescribed medication. A larger proportion of participants endorsed greater rates of nonadherence in adolescents compared with children. Forgetfulness, being asymptomatic, and poor organization were identified as perceived primary adherence barriers for patients and families by survey participants.

Participants were asked to rate how important they perceive routine adherence monitoring to be in clinical practice, from "not important at all" to "very important". Responses were as follows: neutral (3.9\%), important (35.1\%), and very important (61\%). No participants rated adherence monitoring as "not important at all" or "not important at all". Participants were also asked to rate the level of impact they perceive medication adherence to have on patients' clinical outcomes, from "none" to "a lot". The majority of respondents endorsed perceived impact as "a lot" ( $82.5 \%)$. Additionally, participants were asked to rate the level of change they feel they can elicit in patients' adherence barriers, on a scale ranging from "none" to "a lot." Approximately $20 \%$ endorsed feeling that they can elicit "a lot" of change and $72.1 \%$ endorsed "some." Finally, participants were asked to identify primary barriers to doing routine adherence monitoring and intervention as part of standard clinical care (Table 4). The most frequently endorsed responses included lack of clinic time (73.4\%), lack of manpower and resources (64.3\%), and lack of staff with skills/expertise to target adherence and provide intervention (63.6\%).

\section{Discussion}

To our knowledge, this is the first study to summarize current adherence monitoring and intervention practices in pediatric GI and hepatologic care across the USA. Our survey identified current practices across adherence monitoring and intervention, examined the most common barriers to 
Table 4 General practice perspectives $(n=154)$

\begin{tabular}{l} 
Practice characteristic \\
\hline Poor/low adherence defined \\
Patient misses at least $25 \%$ of medication doses \\
Patient misses at least $50 \%$ of medication doses \\
Patient misses at least $75 \%$ of medication doses \\
Patient misses at least $100 \%$ of medication doses \\
Other (eg, combination of factors, missed \\
appointments, missed labs, poor follow-through with \\
behavior plan) \\
Perceived importance of routine adherence monitoring \\
in clinical practice \\
Not important at all \\
Not important \\
Neutral \\
Important \\
Very important \\
Perceived impact of medication adherence on patients' \\
clinical outcomes \\
None \\
Very little \\
Neutral \\
A lot
\end{tabular}

Perceived ability to elicit change in patients' adherence behaviors

None

Very little

Neutral

Some

A lot

Perceived barriers to routine adherence monitoring in clinical care

Lack of manpower and resources

Lack of staff with skills/expertise to target adherence and provide intervention

Lack of clinic time

Lack of clinic space

Adherence is not a priority of our clinical care

Other (eg, insurance reimbursement)

Perceived individual responsible to provide adherence

intervention

Nursing staff

Physician

Nurse practitioner

Psychologist

Social worker

Other (eg, parents, pharmacist)

Primary adherence barriers for children and adolescents Forgetfulness

Poor organization

Interference with extracurricular activities

Difficulty swallowing pills

Side effects

Being away from home

Changes in daily schedule/routine

Not wanting to feel different from other youth

Belief that medication is not working

Complexity of medication regimen
Table 4 (Continued)

\begin{tabular}{ll}
\hline Practice characteristic & $\%$ (n) \\
\hline Misunderstanding directions for taking medications & II.7 (I8) \\
Feeling fine, being asymptomatic & $54.5(84)$ \\
Cost & $7.8($ I 2$)$ \\
Other (eg, taste/texture of medication, parent & $5.2(8)$ \\
attitudes) & \\
Proportion of children (ages 0-I2) taking $<80 \%$ of & \\
prescribed medication & \\
$<25 \%$ & $47.4(73)$ \\
$26 \%-50 \%$ & $42.9(66)$ \\
$51 \%-75 \%$ & $7.1(\mathrm{II})$ \\
$>75 \%$ & $2.6(4)$ \\
Proportion of adolescents (ages I3+) taking $<80 \%$ of & \\
prescribed medication & \\
$<25 \%$ & $14.9(23)$ \\
$26 \%-50 \%$ & $5 \mathrm{I.3}(79)$ \\
$51 \%-75 \%$ & $29.9(46)$ \\
$>75 \%$ & $3.9(6)$ \\
\hline
\end{tabular}

implementing this in practice, and evaluated general attitudes toward adherence monitoring. Overall, data suggest significant variability in practices.

There are several notable strengths to current adherence practices, starting first with the high proportion of participants who endorsed doing adherence monitoring as part of standard clinical care. It does seem that for many participants, adherence monitoring occurs only for a subset of patients, typically based on diagnosis or treatment regimen. Most pediatric GI/hepatologic providers rely on patient and caregiver self-report of adherence, which have not shown great accuracy and usually result in overestimates of medication adherence. ${ }^{6,15}$ However, approximately half of pediatric GI/hepatologic providers are using objective measures as markers of adherence, including blood assays, lab values, and patient response to treatment/medication. It remains unclear whether these objective measures are being sought specifically for purposes of adherence monitoring. Providers are encouraged to exercise caution when using patient/parent-report of adherence, as it is not uncommon for patients/parents to experience difficulty remembering missed doses, or to inflate adherence estimates in order to be viewed favorably by their medical providers. A multimethod approach to adherence assessment which combines subjective and objective measures, for example, self-report and pharmacy records, is likely to provide the most valid estimates of patient adherence.

Another strength of current adherence practice is the high prevalence of providers who deliver targeted intervention to patients with poor adherence. This is done either by identifying and targeting adherence barriers and/or providing 
education to families about the importance of adherence, or about strategies to improve medication-taking. This is notable given that greater adherence barriers are associated with greater difficulty in following prescribed medical regimens. ${ }^{16,17}$ Relatedly, adherence promoting interventions, which specifically identify adherence barriers and utilize problem-solving skills training to address these barriers, have shown great promise in pediatric $\mathrm{IBD}^{18-20}$ and other pediatric populations..$^{21,22}$ Identifying and targeting adherence barriers is thus an essential first step toward improving patient adherence. Also, the goal of education is to increase patient's/family's knowledge of the disease, treatment, and the importance of adherence. There is evidence that educational approaches are effective when combined with behavioral strategies, but they appear to produce insignificant change in adherence when used in isolation. ${ }^{23}$

Shared responsibility across disciplines for monitoring patient adherence and providing intervention is yet another strength of current adherence practices, as each member of the medical team can address different areas of need. Physicians and nurse practitioners might target education about the disease and treatment, education regarding the importance of adherence, and guided problem-solving concerning adherence barriers, while behavioral health providers (eg, psychologist, social worker) might address psychosocial factors impeding adherence. In fact, adherence promotion intervention that is delivered by medical providers among youth with chronic medical conditions has been evaluated and shown to be effective at improving patient adherence. ${ }^{24}$ One study, which evaluated the effectiveness of a nurse-administered adherence intervention among youth with HIV, revealed significant improvements in patient knowledge of their disease and treatment, medical refill history, and self-reported adherence. ${ }^{25}$ Shared responsibility for patient adherence is likely to be most effective when roles and responsibilities are clearly defined and communicated among team members. Without clear communication, team members might pass on the responsibility for adherence monitoring/intervention or incorrectly assume that someone else is targeting a patient's adherence.

Survey participants endorsed a number of barriers to conducting routine adherence monitoring in clinical care, which might partly explain participants' low ratings of the quality of both adherence monitoring and intervention in their practice. Such barriers might also explain why over $70 \%$ of respondents perceived having only "some" impact on patient adherence behaviors, despite perceiving adherence monitoring to be very important and as having significant impact on clinical outcomes. Primary barriers included lack of manpower and resources, lack of staff with skills/expertise to target adherence and provide intervention, and lack of clinic time. While some of these barriers can be difficult and time consuming to remedy, clinical recommendations for providers looking to implement adherence monitoring and intervention are available. ${ }^{26}$ These might include asking patients about difficulty in sticking to a medication regimen at every clinic visit, providing patients with pill boxes and/or a list of smartphone apps designed to provide medication-taking reminders, or collaboration with social work and psychology to address psychosocial adherence barriers. In addition, self-report questionnaires that assess adherence and adherence barriers are available, many of which are validated, quick to administer and score, require little to no training, and are clinically useful to guide appropriate and timely intervention. ${ }^{27}$ It is also noteworthy that most participants underestimated the proportion of children and adolescents experiencing poor adherence. Research has actually shown that across pediatric conditions at least $50 \%$ are not taking medication as prescribed. ${ }^{2}$ This discrepancy between provider estimates and published adherence rates might deter providers from prioritizing medication adherence as a pertinent clinical target during patient visits.

Overall, our study sample consisted of providers with diverse practices and clinical experiences across the USA, thereby enhancing the generalizability of study findings. Generalizability to private practices or other settings, however, may be low given that most participants practiced within children's hospital settings, either free-standing or housed within a larger hospital. In addition, participants largely comprised physicians, nurse practitioners, and psychologists, all provider types who were identified by participants as being primarily tasked with adherence monitoring and/or intervention. This suggests that study findings are likely an accurate representation of current clinical practices surrounding adherence in pediatric GI and hepatologic care. Despite high nonadherence rates in pediatric gastroenterology and hepatology, little is known about clinical practices around adherence to prescribed treatment regimens in this field. Improved understanding about current adherence monitoring and intervention practices is therefore an important step toward developing a more comprehensive, evidence-based, and systematic approach to promoting adherence in pediatrics. This might ultimately promote better adherence behaviors across the pediatric to adult care continuum. Since the current study relied on subjective reports of clinical practices by providers, findings may be an overestimate of adherence 
monitoring and intervention practices. Future studies that employ objective (eg, observational) methods to evaluate adherence practices might provide more valid estimates. By evaluating the extent to which pediatric GI programs are incorporating objective outcomes assessment and utilizing evidence-based adherence interventions, we will be able to identify gaps and future directions in program development to improve adherence and, ultimately, health outcomes in youth with GI and hepatologic disorders.

\section{Disclosure}

The authors report no conflicts of interest in this work.

\section{References}

1. Sabate E, Organization WH. Adherence to Long-Term Therapies: Evidence for Action. Geneva: World Health Organization; 2003.

2. Rapoff M. Adherence to Pediatric Medical Regimens. New York, NY, USA: Kluwer Academic; 2010.

3. McGrady ME, Hommel KA. Medication adherence and health care utilization in pediatric chronic illness: a systematic review. Pediatrics. 2013;132(4):730-740.

4. Osterberg L, Blaschke T. Adherence to medication. $N$ Engl J Med. 2005;353(5):487-497.

5. Logan D, Zelikovsky N, Labay L, Spergel J. The illness management survey: identifying adolescents' perceptions of barriers to adherence. J Pediatr Psychol. 2003;28(6):383-392.

6. Hommel KA, Davis CM, Baldassano RN. Objective versus subjective assessment of oral medication adherence in pediatric inflammatory bowel disease. Inflam Bowel Dis. 2009;15(4):589-593.

7. Ingerski LM, Baldassano RN, Denson LA, Hommel KA. Barriers to oral medication adherence for adolescents with inflammatory bowel disease. J Pediatr Psychol. 2010;35(6):683-691.

8. Schurman JV, Cushing CC, Carpenter E, Christenson K. Volitional and accidental nonadherence to pediatric inflammatory bowel disease treatment plans: initial investigation of associations with quality of life and disease activity. J Pediatr Psychol. 2011;36(1):116-125.

9. Kane S, Huo D, Aikens J, Hanauer S. Medication nonadherence and the outcomes of patients with quiescent ulcerative colitis. Amer J Med. 2003;114(1):39-43.

10. Higgins PD, Rubin DT, Kaulback K, Schoenfield PS, Kane SV. Systematic review: impact of non-adherence to 5-aminosalicylic acid products on the frequency and cost of ulcerative colitis flares. Aliment Pharmacol Ther. 2009;29(3):247-257.

11. Fredericks EM, Lopez MJ, Magee JC, Shieck V, Opipari-Arrigan L. Psychological functioning, nonadherence and health outcomes after pediatric liver transplantation. Am J Transplant. 2007;7(8):1974-1983.

12. Dobbels F, Van Damme-Lombaert R, Vanhaecke J, De Geest S. Growing pains: non-adherence with the immunosuppressive regimen in adolescent transplant recipients. Pediatr Transplant. 2005;9(3):381-390.
13. Aitken M, Valkova S. Avoidable Costs in US. Healthcare: The $\$ 200$ Billion Opportunity from Using Medicines More Responsibly. Parsippany, NJ, USA: IMS Institute for Healthcare Informatics; 2013.

14. Harris PA, Taylor R, Thielke R, Payne J, Gonzalez N, Conde JG. Research electronic data capture (REDCap) - a metadata-driven methodology and workflow process for providing translational research informatics support. J Biomed Inform. 2009;42(2):377-381.

15. Modi AC, Lim CS, Yu N, Geller D, Wagner MH, Quittner AL. A multimethod assessment of treatment adherence for children with cystic fibrosis. J Cyst Fibros. 2006;5(3):177-185.

16. Simons LE, McCormick ML, Devine K, Blount RL. Medication barriers predict adolescent transplant recipients' adherence and clinical outcomes at 18-month follow-up. J Pediatr Psychol. 2010;35(9):1038-1048.

17. McCormick King ML, Mee LL, Gutierrez-Colina AM, Eaton CK, Lee JL, Blount RL. Emotional functioning, barriers, and medication adherence in pediatric transplant recipients. J Pediatr Psychol. 2014;39(3): 283-293.

18. Hommel KA, Hente E, Herzer M, Ingerski LM, Denson LA. Telehealth behavioral treatment for medication nonadherence: a pilot and feasibility study. Eur J Gastroenterol Hepatol. 2013;25(4):469-473.

19. Hommel KA, Hente EA, Odell S, et al. Evaluation of a group-based behavioral intervention to promote adherence in adolescents with inflammatory bowel disease. Eur J Gastroenterol Hepatol. 2012;24(1): 64-69.

20. Hommel KA, Herzer M, Ingerski LM, Hente E, Denson LA. Individuallytailored treatment of medication nonadherence: a Pilot Study. J Pediatr Gastroenterol Nutr. 2012;53(4):435-439.

21. Wysocki T, Harris MA, Buckloh LM, et al. Effects of behavioral family systems therapy for diabetes on adolescents' family relationships, treatment adherence, and metabolic control. J Pediatr Psychol. 2006; 31(9):928-938.

22. Modi AC, Guilfoyle SM, Mann KA, Rausch JR. A pilot randomized controlled clinical trial to improve antiepileptic drug adherence in young children with epilepsy. Epilepsia. 2016;57(3):e69-e75.

23. Kahana S, Drotar D, Frazier T. Meta-analysis of psychological interventions to promote adherence to treatment in pediatric chronic health conditions. J Pediatr Psychol. 2008;33(6):590-611.

24. Rohan JM, Drotar D, Perry AR, McDowell K, Malkin J, Kercsmar C. Training health care providers to conduct adherence promotion in pediatric settings: an example with pediatric asthma. Clin Pract Pediatr Psychol. 2013;1(4):314-325.

25. Berrien VM, Salazar JC, Reynolds E, McKay K; HIV Medication Adherence Intervention Group. Adherence to antiretroviral therapy in HIV-infected pediatric patients improves with home-based intensive nursing intervention. AIDS Patient Care STDs. 2004;18(6):355-363.

26. Hommel KA, Greenley RN, Maddux MH, Gray WN, Mackner LM. Selfmanagement in pediatric inflammatory bowel disease: a clinical report of the North American Society for pediatric gastroenterology, hepatology, and nutrition. J Pediatr Gastroenterol Nutr. 2013;57(2):250-257.

27. Nguyen TM, La Caze A, Cottrell N. What are validated self-report adherence scales really measuring?: a systematic review. $\mathrm{Br} J \mathrm{Clin}$ Pharmacol. 2014;77(3):427-445.
Therapeutics and Clinical Risk Management

\section{Publish your work in this journal}

Therapeutics and Clinical Risk Management is an international, peerreviewed journal of clinical therapeutics and risk management, focusing on concise rapid reporting of clinical studies in all therapeutic areas, outcomes, safety, and programs for the effective, safe, and sustained use of medicines. This journal is indexed on PubMed Central, CAS,

\section{Dovepress}

EMBase, Scopus and the Elsevier Bibliographic databases. The manuscript management system is completely online and includes a very quick and fair peer-review system, which is all easy to use. Visit $\mathrm{http}: / /$ www.dovepress.com/testimonials.php to read real quotes from published authors. 